\title{
A Case Study on the Relationship between Individual Differences and English Pragmatic Competence of Non-English-Major Chinese Postgraduates
}

\author{
Caifen Chen ${ }^{1}$ \\ ${ }^{1}$ School of Foreign Languages, East China University of Technology, Nanchang, China \\ Correspondence: Caifen Chen, School of Foreign Languages, East China University of Technology, Nanchang, \\ China.
}

Received: February 8, 2017

Accepted: February 22, 2017

Online Published: March 1, 2017

doi:10.5430/elr.v6n1p58

URL: https://doi.org/elr.v6n1p58

\begin{abstract}
In the field of pragmatics, a lot of research has been done concerning the pragmatic failures committed by college students. Little research is oriented to the non-English-major postgraduates (NEMP). For that reason, this paper attempts to study the pragmatic competence of NEMP, especially the relationship between pragmatic competence and their individual differences, such as gender differences and differences among different majors, age and working experience. A questionnaire was administrated to 115 non-English-major postgraduates in East China University of Technology (ECUT) in China. The questionnaire consists of an English pragmatic competence test with 25 multiple choices, which was selectively taken from He Ziran's study (1988). By using both quantitative and qualitative analysis, the study offers the following findings: the general level of NEMP's pragmatic competence is quite low at present, but with their developing cultural awareness, they do a better job in sociopragmatic competence than that in pragmalinguistic competence; there are significant differences between different genders and their pragmatic competence, with the females' pragmatic competence higher than males', while the differences among majors, age and working experience are not so significant in the participants' English pragmatic competence. The paper also offers some suggestions for postgraduates' English teaching: using different teaching methods should be considered; Input of English pragmatic knowledge in proper contexts and making best use of Internet should be increased as well; the postgraduates' individual differences should also be treated appropriately in English teaching.
\end{abstract}

Keywords: Pragmatic competence, Gender differences, Non-English-Major Postgraduates

\section{Introduction}

The higher education in China has developed quickly, which not only provides more talents for the country, but also brings a big challenge for the postgraduates to devote themselves to the society. It is urgent for the postgraduates to grasp the ability of cross-cultural communication and, first of all, they need to acquire English pragmatic competence.

Scholars made a lot of research on second language learners' pragmatic competence shortly after Chomsky (1977) brought out the term "pragmatic competence". Since the 1980s, Chinese researchers have investigated the pragmatic competence of English learners in China (He Ziran \& Yan Zhuang 1986; Wang Dexing 1990; Hong Gang 1991; Dong Xiaohong 1994). All the results indicate the Chinese English learners' pragmatic competence is at a low level and it cannot be improved naturally with the development of their linguistic competence. Dai Weidong (2005) notices the importance of classroom instruction in developing L2 learners' pragmatic competence. By reviewing the latest interlanguage studies abroad and the demerits of L2 teaching and learning at home, he discusses the necessity and feasibility to develop L2 pragmatic instruction and puts forward to a model of explicit instruction. Some scholars also explore the importance and necessity of teaching culture in the development of L2 learners' pragmatic competence (Si Lianhe, 2001).

Concerning the research on IDs (Individual Differences) such as age, gender, motivation and learning strategy in L2 pragmatic development, Kasper \& Rose make a comprehensive review of the studies in 2002, which provides a new perspective in enhancing the postgraduates' pragmatic competence. 
The main task of the thesis (paper) is to find out the correlation between individual differences and pragmatic competence. In order to explain to what extent the individual differences influence the level of pragmatic competence, the researcher is trying to find out the correlation between the pragmatic competence and the individual differences such as gender, major and working experience. The present study has certain significance in theory and practice. Theoretically, it attempts to find factors which influence the non-English-major postgraduates' pragmatic competence. Practically, it is advisable for teachers not only to teach students pragmatic knowledge, but also pay more attention to the individual differences and the pragmatic awareness to improve their pragmatic competence from another perspective; Moreover, it enlightens and helps people who engage in education, translation and diplomacy to understand language more accurately and to use it more effectively.

\section{Literature Review}

The ability to understand another speaker's intended meaning is called pragmatic competence. Discussions about pragmatic competence can be traced back to Chomsky (1977). Many scholars express more viewpoints on pragmatic competence. Chomsky (1977) holds the view that pragmatic competence is defined as the knowledge of the condition and manner of appropriate use. In line with Leech's (1983) division of linguistics into "grammar" and "pragmatics", a person's "linguistic competence" is made up of grammatical competence and pragmatic competence. In Bialystok's (1993) opinion, pragmatic competence refers to a variety of abilities concerned with the use and interpretation of language in contexts. Chinese scholar Liu Shaozhong (1997) claims that pragmatic competence refers to the language user's ability to realize what context he or she is in, and what the speaker means and how to convey his or her intention properly. He Ziran (2003) considers pragmatic competence as the ability to use language and understand language in context appropriately so as to attain a specific purpose. Both Bialystok's and Liu's claims are thorough enough to have taken the speaker's and the hearer's competence into consideration.

\subsection{Pragmatic Failure}

Pragmatic failure means that when the learners misunderstand the particular context and utterance styles in cross-cultural communication, they would easily commit errors. Jenny Thomas first proposed the concept of pragmatic failure in 1983. Thomas (1983) points out the cross-cultural pragmatic failure---the abuse or misuse of the native culture in foreign context, would arouse misunderstanding, conflict and even hatred; Kasper (1989) assumes that when the learners apply the stereotypes in the first language word by word to the target language, or translate the first language word by word into the target language literally, or misuse the pragmatic methods and measures in the target language, pragmatic failure usually occurs; in cross-cultural communication, people often encounter misunderstanding, though there is no trouble in understanding the literal meaning of their utterances; with the ever-expanding global village, such pragmatic failure, is attracting more and more attention. Gao Yuan (1996) holds that pragmatic failures occur because of inappropriate timing, style, situation or habit of utterance; He Ziran (1997) declares that pragmatic failures aren't the errors the learners commit when they use linguistic knowledge such as words, phrases and sentences. Moreover, different countries share different values, customs and religions, ways of thinking, etc. As a result, we should bear in mind that cultural differences are very important when communicating with foreigners.

\subsection{Individual Differences and Pragmatic Competence}

Individual differences are, "enduring personal characteristics that are assumed to apply to everybody and on which people differ by degree" (Dörnyei, 2005). It has been suggested that individual differences (IDs), as opposed to universals in language learning (Diller, 1981), also impact the way in which a second language is learned. Scholars and practitioners of adult second language learning traditionally have cast the issue of individual differences in terms of such constructs as aptitude, motivation, learning strategies, learning styles, meta-linguistic awareness, and personality traits (e.g., extraversion), as well as a range of other social and affective variables (Ehrman, Leaver \& Oxford, 2003). Although a comprehensive theory of IDs in SLA does not yet exist (Oxford, 1990b; Skehan, 1989), Ellis (1994) has classified three groups of IDs: (a) learner beliefs, (b) affective states (The affective variable that has attracted most attention is anxiety.), and (c) general factors (Age, Language aptitude, Learning style, Personality, Motivation, Learning Experience, Learning strategies, Learning outcomes). General factors, also called demographic variables by Oxford (1990b), include aptitude, gender, motivation, personality, learning style and age. They are considered to be relatively stable, whilst learner beliefs and affective states are considered less so. How any IDs, and how demographic variables in particular, relate to learning conditions, strategy choice and strategy training, remains unclear.

There is some consensus that learning should not be a mechanical, stimulus-response process; rather, it should be a creative constructive process and learners should control their learning process consciously (Ellis, 1994). Studies on 
teaching methods begin to give way to studies on language learners because individual differences of language learners are found to play an important role in language learning. It has also been found that some learners are always more successful than others when the external environment is nearly equal. So the investigations of the learners have become one of the major concerns in foreign language teaching and research, for Learner differences play a great role in language learning. Individual differences, which may consist of the following aspects: learning motivation, learner strategies, learners' personality, sex, age and so on, have been involved in second language acquisition research from an early stage but are still vacant in the scope of second language pragmatic competence. So it is worthy of attention and further research. In the following section, relation between individual differences such as genders, age, major and working experience and pragmatic competence will be discussed in detail.

\subsubsection{Gender Differences and Pragmatic Competence}

Most research on the relation of learner gender and SLA has been concerned with cognitive style or learning strategies, or to issues of what variety of L2 is being acquired or opportunities for input and interaction. There is widespread belief in many western cultures that females tend to be better L2 learners than males, but this belief is probably primarily a social construct, based on outcomes that reflect cultural and sociopsychological constraints and influences. There do appear to be some gender differences in language acquisition and processing, but the research evidence is mixed. For example, according to Kimura (1992), women outperform men in some tests of verbal fluency (such as finding words that begin with a certain letter), and women's brains may be less asymmetrically organized than men's for speech. Of particular potential relevance to SLA are findings in relation to mental representations in the lexicon versus the grammar.

According to these findings, females seem to be better at memorizing complex forms, while males appear to be better at computing compositional rules (Halpern, 2000). Other differences may be related to hormonal variables. Higher androgen level correlates with better automatized skills, and high estrogen with better interpretive skills. Wang Xuemei (2006) states that although gender related differences are an important part of individual differences, the relevant studies only lay special emphasis on male and female's differences in phonetics, vocabulary, communication patterns and language taboo, etc. In the area of second language acquisition, especially in students' linguistic and pragmatic competence, such kind of researches are rare.

\subsubsection{Age Differences and Pragmatic Competence}

Age is also an important variable in second language learning. Lenneberg (1967) speculates that the critical period applies to SLA as well as to first language acquisition, and this counts for why almost all L2 speakers have a "foreign accent" if they do not begin learning the language before the cutting-off age. Long (1990) argues instead that there are multiple periods which place constraints on different aspects of language: e.g. different periods relate to the acquisition of phonology versus the acquisition of syntax. They also suggest that these periods do not impose absolute cut-off points; it is just that L2 acquisition will more likely be complete if begun in childhood than at a later age. This claim seems true since some older learners can achieve native-like proficiency, although they definitely constitute a minority of second language learners.

While most would agree that younger learners achieve ultimately higher levels of L2 proficiency, evidence is just as convincing that adolescents and adults learn faster in initial stages. While "brain plasticity" is listed as a younger learner advantage, older learners are advantaged by greater learning capacity, including better memory for vocabulary. Greater analytic ability might also be an advantage for older learners, at least in the short run, since they are able to understand and apply explicit grammatical rules. Newport (1990) suggests that "less is more" in this aspect. One reason younger learners develop more native-like grammatical intuitions, is that they are in a non-analytic processing mode. This calls for another qualification: younger learners are probably more successful in informal and naturalistic L2 learning contexts, and older learners in formal instructional settings. Other advantages that younger learners may have been less inhibited than older learners, and having weaker feelings of identity with people (other than close family or caregivers) who speak the same native language. So, this paper is quite of great significance from the postgraduates' view.

\section{Methodology}

\subsection{The Participants}

115 first-year non-English-major postgraduates were chosen from ECUT (East China University of Technology) (see Table 1) from different majors, including 52 females and 63 males. Their average age is 24 years old with the oldest one 38 and the youngest one 21; among the 115 postgraduates there are 36 postgraduates with working experience varying from half a year to 17 years. 
Table 1. Basic information of the participants

\begin{tabular}{ll}
\hline Age & $21-38$ \\
Gender & 52 females; 63 males \\
Major & 52 postgraduates from MA programs \\
& 63 postgraduates from MS programs \\
\hline Working experience & 36 postgraduates with working experience \\
& 79 postgraduates without working experience \\
\hline
\end{tabular}

\subsection{Instruments}

The instruments in the study is the questionnaire---He Ziran's (1988) Pragmatic Competence Questionnaire.

The questionnaire used in this survey is based on the ones developed by Prof. He Ziran (1988), which is of high validity and reliability. As an optimal data-gathering technique, the questionnaire is available to examine the pragmatic competence level of the subjects.

The questionnaire is made up of 25 items (see Appendix I) (The researcher omitted 3 items from the original questionnaire of He Ziran (1988), changing 28 items to 25 items considering the subjects' educational background.). Each item consists of four multiple choices, offering different interactive situations such as how to greet, how to express apology, how to take a leave, etc. What the participants need to do is just to pick out the appropriate answers. The full mark of the questionnaire is 100 and the passing line is 60 .

The 25 items are supposed to test the postgraduates' pragmalinguistic and sociopragmatic competence. Items 1, 2, 14, $15,16,18,20,22,23,24,25$ belong to the former category and Items $3,4,5,6,7,8,9,10,11,12,13,17,19,21$ belong to the latter. Pragmalinguistic competence requires mappings of form, meaning, force and context, which are sometimes obligatory and sometimes not. Sociopragmatics refers to the link between action-relevant context factors and communicative action and not necessarily require any links to specific linguistic forms at all.

\subsection{Data Collection and Analysis}

First of all, the English teachers helped to distribute the questionnaire in the classroom; then, the participants were required to finish the 25 multiple choices in half an hour. Besides, they were required to write down other variables such as age, major and working years. The research was done in the participants' own classrooms during regular class-time in order to minimize the impact of the environment. Before the questionnaire was distributed to the students, it was made clear to them that the purpose was to test their pragmatic competence; the postgraduates didn't need to worry about the results, for the answers would only be used for the purpose of research and there's nothing to do with their evaluation of English achievement. They had to do the questionnaire individually. If they had any linguistic problems, they were allowed to consult the teacher.

The results of the questionnaires were analyzed by using the SPSS (Statistical Package for Social Science) version 13.0 and Microsoft Excel 2003. This survey employed both quantitative and qualitative analysis. Data-analysis included the following steps:

(1) Descriptive statistics, including means, standard deviation, etc., were computed to evaluate the students' present pragmatic competence level.

(2) Independent-samples T-test to testify the gender differences and differences among different age, majors and having working experience or not.

\section{Results and Findings}

In the study, 115 postgraduates in ECUT are involved and their general state of pragmatic competence is described as follows:

We can get an overview of the participants' pragmatic competence from Table 2, which shows the distribution of the scores of the participants from the lowest score of 36 to the highest one of 80 . Most participants' scores are centralized at the span from the score of 52 to $64.51 .3 \%$ participants are under the passing line. Those who get score of 36 account for $4.3 \%$ and $1.7 \%$ for the score of 80 , while $19.1 \%$ gets the score of 60 . 
Table 2. Scores of Pragmatic Competence

\begin{tabular}{llllll}
\hline & & & & & Cumulative \\
\hline Valid & 36 & 5 & Percent & Valid Percent & Percent \\
& 40 & 5 & 4.3 & 4.3 & 4.3 \\
& 44 & 8 & 4.3 & 4.3 & 8.7 \\
& 48 & 7 & 7.0 & 7.0 & 15.7 \\
& 52 & 15 & 6.1 & 6.1 & 21.7 \\
& 56 & 19 & 13.0 & 13.0 & 34.8 \\
& 60 & 22 & 16.5 & 16.5 & 51.3 \\
& 64 & 19 & 19.1 & 19.1 & 70.4 \\
& 68 & 8 & 16.5 & 16.5 & 87.0 \\
& 72 & 4 & 7.0 & 7.0 & 93.9 \\
& 76 & 1 & 3.5 & 3.5 & 97.4 \\
Total & 80 & 2 & .9 & .9 & 98.3 \\
& 115 & 1.7 & 1.7 & 100.0 \\
\hline
\end{tabular}

To get a clear mind about the postgraduates' pragmatic competence, we can get more details from the Table 3 and more straight impression from Figure 1.

Table 3. Statistics of Students' Pragmatic Competence

\begin{tabular}{lll}
\hline $\mathrm{N}$ & Valid & 115 \\
& Missing & 0 \\
\hline Mean & & 56.66 \\
Std. Error of Mean & .889 \\
Median & 56.00 \\
Mode & 60 \\
Std. Deviation & 9.536 \\
Minimum & 36 \\
Maximum & 80 \\
\hline
\end{tabular}




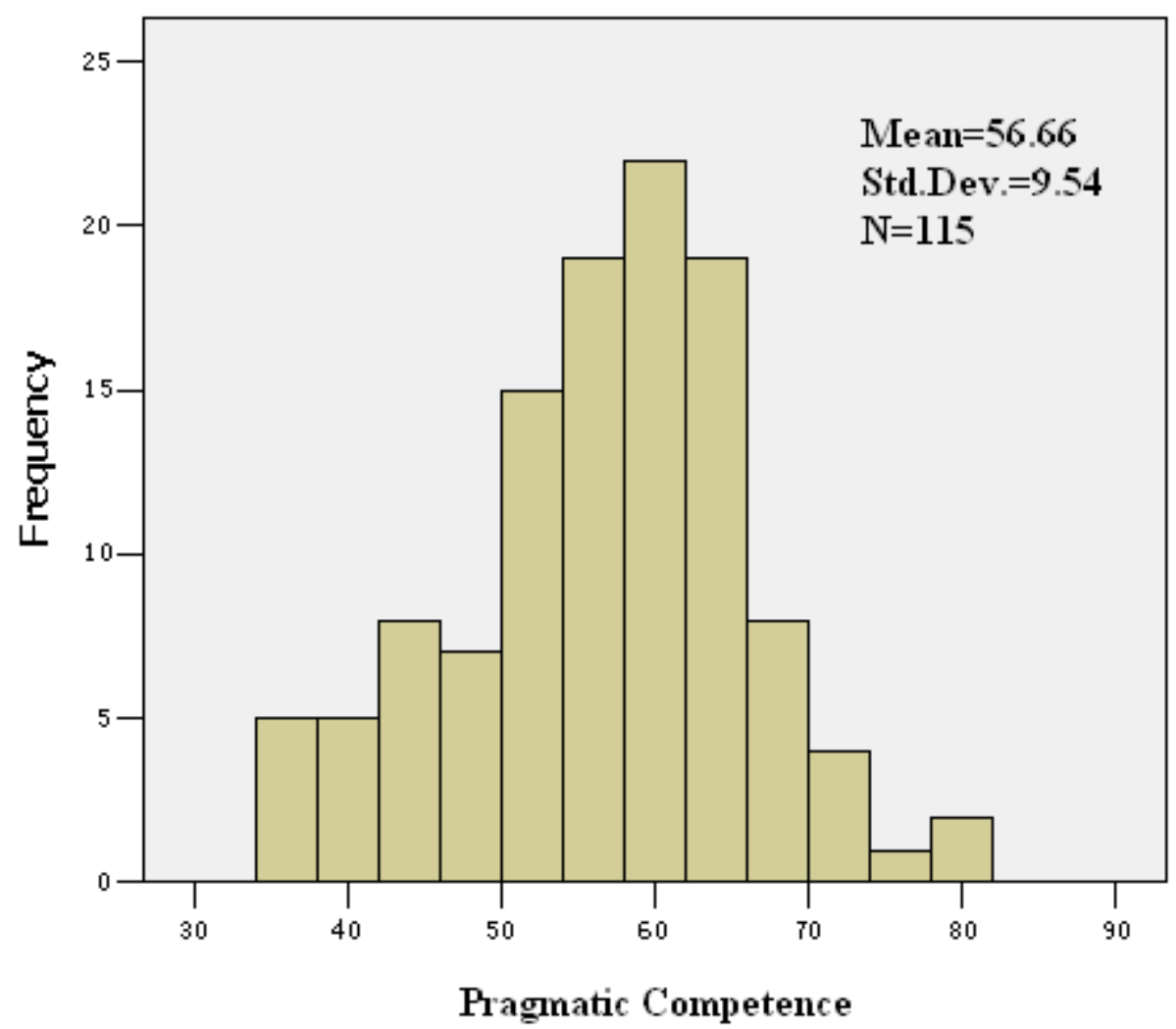

Figure 1. Histogram of Postgraduates' Pragmatic Competence

In Table 3, statistic analysis shows that the mean of the participants' pragmatic competence level is 56.66 , which is below the passing line, rather lower than we expected. What's more, we can directly perceive the scores' distribution from the Histogram (Figure 1). From the figures we can draw a conclusion that the postgraduates' pragmatic competence is still at a low level.

Many studies have found that learners' individual differences play very important roles in their language learning process and even somehow lead to the success of their learning activities. Individual differences, which may consist of such aspects as learning motivation, learner strategies, learners' personality, sex, age and so on, have been involved in second language acquisition research from an early stage but is still vacant in the scope of second language pragmatic competence. So it is worthy of attention and further research. In the study, we took such factors as gender, age, major, and working experience into consideration to see the correlations with their pragmatic competence. In the following section, all these four factors will be discussed in detail.

\subsection{Gender Differences in English Pragmatic Competence}

In the study, the subjects involved 52 females and 63 males. From table 4 we can see that there are significant differences between males and females in the scores of pragmatic competence questionnaire $(t=-2.611$, sig. $=.01)$ and females got higher scores than males in this questionnaire. 
Table 4. The T-test of Different Genders in Pragmatic Competence Questionnaire

\begin{tabular}{llllll}
\hline & Gender & $\mathrm{N}$ & Mean & Std. Deviation & Std. Error Mean \\
\hline Score & Male & 63 & 54.60 & 9.776 & 1.232 \\
& Female & 52 & 59.15 & 8.689 & 1.205 \\
\hline
\end{tabular}

\begin{tabular}{|c|c|c|c|c|c|c|c|c|c|c|}
\hline & & \multicolumn{4}{|c|}{$\begin{array}{l}\text { Levene's Test } \\
\text { for Equality of } \\
\text { Variances }\end{array}$} & \multicolumn{3}{|c|}{$\mathrm{t}$-test for Equality of Means } & \multirow{2}{*}{\multicolumn{2}{|c|}{$\begin{array}{l}95 \% \text { Confidence } \\
\text { Interval of the } \\
\text { Difference }\end{array}$}} \\
\hline & & \multirow[t]{2}{*}{$\mathrm{F}$} & \multirow[t]{2}{*}{ Sig. } & \multirow[t]{2}{*}{$\mathrm{t}$} & \multirow[t]{2}{*}{ df } & \multirow[t]{2}{*}{$\begin{array}{l}\text { Sig. } \\
\text { (2-tailed) }\end{array}$} & \multirow[t]{2}{*}{$\begin{array}{l}\text { Mean } \\
\text { Difference }\end{array}$} & \multirow[t]{2}{*}{$\begin{array}{l}\text { Std. Error } \\
\text { Difference }\end{array}$} & & \\
\hline & & & & & & & & & Lower & Upper \\
\hline Score & $\begin{array}{l}\text { Equal } \\
\text { variances } \\
\text { assumed }\end{array}$ & 1.103 & .296 & -2.611 & 113 & .010 & -4.55 & 1.743 & -8.003 & -1.098 \\
\hline & $\begin{array}{l}\text { Equal } \\
\text { variances } \\
\text { not } \\
\text { assumed }\end{array}$ & & & -2.641 & 112.354 & .009 & -4.55 & 1.723 & -7.965 & -1.137 \\
\hline
\end{tabular}

This indicates female students are more proficient in language pragmatic aspect. Generally speaking, boys' oral expression is not as good as girls', thus when analyzing the pragmatic aspect of learning tasks (e.g. situation conversation, or interpretation of movie fragment), they are more inclined to be silent, which to some extent influences learning results. The results are consistent with those obtained by Wang Xuemei (2006), who explored gender related differences of the pragmatic competence and linguistic competence of 105 English majors and found that girls are better than boys in spoken English and language pragmatic aspect. The reasons can be explained from three aspects:

First, innate biological differences account for sex-differentiated rates of language acquisition, as well as for differences in psychological orientation or temperament (Buffery \& Gray, 1972; Gottman \& Levenson, 1988) and psychological differences can most account for gender differences. Women care more about making connections and they often seek involvement and focus on interdependence with others while men are more autonomic and they often seek independence and focus on hierarchical relationships. Thus, men often use linguistic strategies that assert control and women often adopt linguistic devices that involve others and emphasize the interpersonal nature of talk.

Second, socialization can be regarded as an explanatory factor (Tannen, 1987). Under different cultures, girls and boys are socialized in different patterns and have different organizational structures and interactive norms. As a result, they interpret language differently. Boys tend to be more competitive and control-orientated; while girls interact more cooperatively and focus on closeness. Women use more standard forms than men relate to the ways in which society treats women. For example, people are tolerant of boys' behavior, while girls' mistakes are very often frowned upon and punished on the spot. Holmes Janet (1992:173) once said, "women are designated the role of modeling correct behavior in the community." From this point, women are expected to speak more correctly and politely.

Third, differential distribution of power in society attributes gender differences. Boys' groups are larger, more inclusive, and more hierarchical, so boys must struggle to avoid the subordinate position in the group; women, powerless members of a subordinate group, choose to be more linguistically polite. For them, talk creates intimacy; but men live in a hierarchical world, where talk maintains independence and status. They are on guard to protect themselves from being put down and pushed around.

\subsection{Age Differences in English Pragmatic Competence}

In the study, the mean age of the 115 subjects is 24 with 53 postgraduates under 24 years old, while 62 postgraduates are 24 or above and 4 of them are above 30 years old. 
Table 5. The T-test of Different ages in Pragmatic Competence Questionnaire

\begin{tabular}{|c|c|c|c|c|c|c|c|c|}
\hline & Age & $\mathrm{N}$ & Mean & $\begin{array}{l}\text { Std. } \\
\text { Deviation }\end{array}$ & $\mathrm{T}$ & $\begin{array}{l}\text { Sig. } \\
\text { (2-tailed) }\end{array}$ & $\begin{array}{l}95 \% \text { Confidence } \\
\text { Difference }\end{array}$ & Interval of the \\
\hline \multirow[t]{2}{*}{ Score } & $<24$ & 53 & 56.45 & 9.304 & \multirow{2}{*}{-.215} & \multirow{2}{*}{.830} & Lower & Upper \\
\hline & $\geq 24$ & 62 & 56.84 & 9.802 & & & -3.935 & 3.163 \\
\hline
\end{tabular}

From table 5 we can see that there are no significant differences about age in the scores of pragmatic competence test $(\mathrm{t}=-.215$, sig. $=.830)(\mathrm{A}$ high significance value for the $\mathrm{t}$-test (typically more than 0.05) displays that there is no significant difference between the two groups) indicates that there is no significant difference between the two group means.). Age has been regarded as an important factor in the ways in which language learners differ, and a vast amount of research has been conducted regarding age effects on second language acquisition (e.g. Birdsong, 1992; DeKeyser, 2000; Oyama, 1976; Patkowski, 1980). It is generally believed that children enjoy an advantage over adults in learning languages because of their 'plasticity'. The Critical Period Hypothesis for second language acquisition has not been conclusively proven by research, nor has it been completely disproved. Brown states that there is "a biologically determined period of life when language can be acquired more easily and beyond which time language is increasingly difficult to acquire." Originally, this hypothesis only included first language acquisition, but later researchers have extended it to second language as well. Most research indicates that CPH does not exist for all aspects of second language acquisition, but there is "powerful evidence of a critical period for accent" according to Brown's opinion. While there are many advantages to an early age for second language acquisition, there is little evidence to support the idea that adults are unable to successfully learn a second language. Because adults possess many inhibitions and attitudes about speaking a foreign language, they are less likely to attempt meaningful learning. The postgraduates are required to take foreign language courses in order to graduate. This research result just supports age effects are quite little on adult learners.

\subsection{Majors Factor in English Pragmatic Competence}

In the study, there are 52 postgraduates who are from MA programs, which including majors of Art, Philosophy, Business \& Management, etc. and 63 postgraduates are from MS programs, which including majors of Chemistry, Electronic Science and Technology, Environmental Engineering, Computer Science, Geoscience and Resource Information, etc.

Table 6. The T-test of Different Majors in Pragmatic Competence Questionnaire

\begin{tabular}{lllllllll}
\hline & Major & $\mathrm{N}$ & Mean & Std. Deviation & $\mathrm{T}$ & Sig. (2-tailed) & 95\% Confidence Interval of the Difference \\
\hline Score & MA & 52 & 56.77 & 10.083 & .110 & .912 & Lower & Upper \\
& MS & 63 & 56.57 & 9.140 & & & -3.357 & 3.753 \\
\hline
\end{tabular}

From table 6 we can see that there are no significant differences about different majors in the scores of pragmatic competence test $(\mathrm{t}=.110$, sig. $=.912)$ indicates that there is no significant difference between the two group means. The result maybe a little surprising, for people always think the postgraduates from MA programs would have better English acquisition than those from MS programs.

\subsection{Having Working Experiences or Not in English Pragmatic Competence}

In the study, 36 postgraduates possess working experience from half a year to 17 years, while 79 postgraduates just graduated from their Bachelor's degree.

Table 7. The T-test of Having Working Experiences Or Not in Pragmatic Competence Questionnaire

\begin{tabular}{|c|c|c|c|c|c|c|c|}
\hline & $\begin{array}{l}\text { Working } \\
\text { Experiences }\end{array}$ & $\mathrm{N}$ & Mean & $\begin{array}{l}\text { Std. } \\
\text { Deviation }\end{array}$ & $\mathrm{T}$ & $\begin{array}{l}\text { Sig. } \\
\text { (2-tailed) }\end{array}$ & $\begin{array}{l}95 \% \text { Confidence Interval of } \\
\text { the Difference }\end{array}$ \\
\hline \multirow[t]{2}{*}{ Score } & Yes & 36 & 54.67 & 9.937 & \multirow{2}{*}{-1.523} & \multirow{2}{*}{.131} & Lower \\
\hline & No & 79 & 57.57 & 9.269 & & & -6.680 \\
\hline
\end{tabular}

From table 7 we can see that there are no significant differences about age in the scores of pragmatic competence test $(\mathrm{t}=-1.523$, sig. $=.131)$. We can regard the postgraduates' working experience as their learning experience. Under the Chinese setting, it's harder for the postgraduates to acquire the pragmatic competence well, whether they had working experience or not. We lack the context and English atmosphere, that's why we see there is no significant difference between the two groups. 
The postgraduates are quite different from the undergraduates. For one hand, the postgraduates achieve more learning experience than undergraduates, that is, many postgraduates have working experiences. Whether working experiences affect the pragmatic competence or not has no decision yet, and few researchers have made research on this topic. That's why the author has put this factor into consideration; for the other hand, the postgraduates' English class is a mixed one, that is, the class consists of postgraduates from different majors, while the undergraduates of the same major form an English class. Some postgraduates are from MA programs, while others are from MS programs. This research also analyzes whether different majors would affect the postgraduates' pragmatic competence or not.

\section{Discussion}

\subsection{Reasons for Pragmatic Failure}

\subsubsection{The Difference of Pragmatic Principle}

From the results of the questionnaire, we can see most postgraduates have no idea about the pragmatic principles. In item10, "when introducing themselves to someone else they don't know at a party", 41 percent of the postgraduates in the questionnaire chose the incorrect one: "May I introduce myself to you and at the same time make your acquaintance?" The students just violated the maxim of quantity in Grice's cooperative principle, a simple reaction of "Hi, I'm..." is enough in such situation.

In item 13, when asked how to greet English teacher, Dr. Johns, outside the classroom, 16 percent of the postgraduates chose the incorrect one: "Hi, Dr. Johns." and 28 percent of the postgraduates chose another incorrect one: "Good morning, teacher Johns." They all violated Leech's politeness principle. Furthermore, the postgraduates didn't realize that "teacher" in English can only refer to a profession and cannot be used as a title, whereas the Chinese semantic equivalent "lao shi" can both refer to a profession and serve as an addressing term. However, Leech's politeness principle is proposed according to western culture. Some are not appropriate to Chinese culture, because China has its own culture features which are totally different from western ones. Prof. Gu Yueguo is one of Chinese scholars who have contributed significantly to the study of politeness. He has proposed four sides of politeness: respectfulness, modesty, attitudinal warmth and refinement.

Comparing Leech's PP with Gu's PP, we can find some differences between them, because of the different cultural backgrounds. Chinese characteristics focus on modesty most. We often heard the postgraduates say "My English is poor", which puzzled the foreign teachers a lot, for they didn't think so. Actually the postgraduates would usually denigrate themselves to show modesty while communicating with the foreigners. But in this case, the English-speaking people would think you are impolite because of denying their praise.

\subsubsection{Different Language Context}

In the item 14 of the questionnaire, only $40 \%$ postgraduates got the correct answer. That's because the postgraduates missed the context in the dialog. Context is a notion used in the language sciences (linguistics, sociolinguistics, systemic functional linguistics, discourse analysis, pragmatics, semiotics, etc.) in two different ways, namely as verbal context and social context (from Wikipedia). According to Jacobson, Language can perform at least seven basic functions as phatic, directive, informative, interrogative, expressive, evocative and performative (Hu, 2003). Style, as stated by Joos (Cited in Francis 1965: 254-55), can be frozen, formal, consultative, casual, and intimate. Different styles should be adopted in different situations. For instance, you'd better not speak to a taxi driver in such a polite way, "Excuse me, would you mind taking me to the hotel?" for it is the driver's duty to take you to wherever you want to go because you pay for his service; it's also because the social distance between you and him that makes it unnecessary to be so indirect. So it's fine to say "Hotel, please".

Among the common words in the English dictionary get has 72 meanings, and face has 23 meanings as a noun and 12 as verb. Language tolerates both polysemy and homonymity heavily because humans are very context-sensitive, unlike a machine translator, which can be tripped up. Noting the various contexts that different English patterns appear is vitally important for English learners. For example, we all know that "How are you?" "Hello!" "Hi! Glad to meet you!" and "Hello, it's nice to meet you!" are greetings. But they are used in different contexts. "How are you?" is informal and is usually used between acquaintances while "Hello" is also informal but it is used by closer friends. When you are introduced to someone in informal situation, you can say "Hi! Glad to meet you!" to greet him/her, but if you are introduced to someone who are elders or has higher social status than you, you may shake hands before you say "Hello, it's nice to meet you!". If English learners can not distinguish slight differences among them and use the greetings freely, pragmatic failure will inevitably occur.

The core of communication is the mutual understanding among the language users. And understanding of a language undoubtedly relies much on context. Word or sentence meaning in a language is not as fixed as it was supposed and would vary in different situations. For example, when you invite someone to see a film by saying "this evening, if 
you have time, we can go to the movie together" and someone just answers "well, I will play it by ear!" In this case, if you understand the sentence only at its semantic level, you will get very confused. And the idiom "play it by ear" in this context means to make the decision at the moment someone need to and not before. So context of language has been the basis of proper use and understanding of language and the failures originating from the learners' poor comprehension of the interlocutor's utterance will impose great impact on the effect of communication and further influence their pragmatic competence.

\subsubsection{Cultural Difference}

The sociopragmatic failure the postgraduates made refers to the error caused by the ignorance of the cultural background in the target language. It often occurs when the postgraduates make cross-cultural communication. They often use the Chinese way of speaking and misuse value judgments and taboos and assess relative power or social distance inappropriately, as a result, sociopragmatic failures occur.

From the table 4, we can see the postgraduates know how to react to foreigners' praise correctly, but most of them don't know how to take a leave. Another case is about the attitude towards old people. Once I offered help to a 65-year-old foreign teacher by turning on the computer for her without her permission in the classroom, she was quite annoyed instead of expressing her thanks to me. She murmured something like she was once a computer teacher and had no difficulty in turning on the computer by herself. I was quite impressed. In China, Respecting old people is a great virtue in China and it's quite common to help and give seats to those old people in overcrowded bus to show respect, but western people do not accept this kind of respect, especially old women. She will consider it a kind of offense or at least impoliteness. So it is quite inappropriate for the students to address an old woman "old lady" as we usually address "Lao taitai" in China.

Many countries share the same free topics such as holidays, jobs, hobbies, local events, etc., but there are taboo topics under different cultures.

Take a look at the following examples:

(1) How old are you?

(2) How much do you earn each month?

(3) Are you married?

The above three topics are even free for the strangers in China, while in western culture they are taboo topics. The westerners put emphasis on individualism and they claim that personal privacy such as income, marital status, religion, cost of a house, political tendency, etc. cannot be interfered. Therefore, in order to create a successful communication, the postgraduates should get a full understanding of the culture of the target language.

Even the social distance shows the culture differences. Different countries also have different rules about social distances. Generally speaking, westerners like to keep 2-4 feet as the personal zone when they talk in earnest about something. The overcrowded nature of some Asian countries means that they are accustomed to talking to others from a very close distance. Unlike western practice, it is very common to see two Chinese of the same gender walking and talking together with one's arm on another's shoulder, or two women talking hand in hand. Generally speaking, the persons of the same gender keep a closer distance in the public than those of different gender in China.

Once a postgraduate greeted his beautiful foreign teacher who knew very little about the Chinese "it s rather cold. You'd better put on more clothes." But the teacher didn't appear happy on hearing this. There is nothing wrong to do with the language. The problem lies within the culture in which the language is used. Americans (and many westerners too) don't like to be told what to do as they tend to be independent; while Chinese are in the habit of showing and accepting concerns. Many postgraduates are puzzled about listening to English jokes, for they usually understand every word, but don't think it is worth laughing. The reason is that sometimes connotations (the implied meanings) of words are key to understanding and that's why language alone doesn't guarantee successful intercultural communication.

\subsubsection{Improper Language Input}

Most postgraduates have learned English for more than 10 years, but their English level still remains poor. Although teaching materials have great effect on the development of postgraduates' language proficiency, it's not easy for the teachers and postgraduates to find appropriate teaching materials in the class and there are not enough textbooks for the teachers to choose comparing with the abundant undergraduates' textbooks. Appropriate teaching materials not only benefit the students, but also reduce a lot of homework for the teachers; otherwise the inappropriate teaching materials would only delay the learning process and lead to unsatisfactory achievements. Since the communicative approach was introduced into China in the 1980s, we have to admit that foreign language teaching in China has been 
enhanced tremendously. In 2006, new innovation appeared in college English teaching, which focused on the communicative abilities of listening and speaking as new teaching goals. It does make great progress for language teaching, but there's still a long way to go. Many English textbooks are edited with Chinglish and lots of dialogues are specific for Chinese culture without concerning the style and context, which will cause pragmatic failure when interact with the target language users; others provide single sentences which are context-stripped; each textbook contains all kinds of exercises, including reading comprehension, words filling, close, substitution drills, translation, and composition etc. What's more, a few of them are compiled from the viewpoint of Chinese, but not from the native speakers of English.

In many universities, the foreign teachers in China teach on their own teaching schedule and prepare lots of supplementary materials without using any textbook. It's quite fresh for Chinese postgraduates at the beginning of the class, but soon many problems arise. While interviewing the postgraduates, we may often hear such complaints: "The topics provided by the foreign teachers are so easy"; "The teaching style is too casual and I don't know what will be taught tomorrow"; "I can't review the class for there's no textbook at all". Such comments revealed that the postgraduates prefer to have textbooks in hand, though they are a little biased towards western teaching style.

When asked to describe the postgraduates in English class in China, many foreign teachers would not hesitate to use such words as "silent", "passive", "obedient" and "rude"; they are puzzled about the postgraduates' heavy dependence on the textbooks and the way they search for answers-they either search for answers through the textbooks by themselves or turn to peers without communicating with the foreign teachers so often. Some argue that the education system in China should be responsible for the students' heavy dependence on textbooks. Actually, it may not be the case.

Therefore, a comprehensive, authentic and systematic textbook is in desperate need and may facilitate the English classroom. A good textbook provides many factors such as framework, syllabus, ready-made texts and tasks, guidance, autonomy, economy and convenience.

\subsection{Countermeasures for Improving the Pragmatic Competence}

To solve this problem, teachers should be sensitive to this kind of differences and take measures to overcome its unfavorable influence. For example, in English class, teachers can let girls make the speech first to enlighten boys and inspire boys to think further. Or teachers can divide students with different gender and pragmatic competence into different groups, and encourage them to complete communication tasks together. When discussing some topics in class, teachers should take gender difference into account and rationally assign the work. It is in favor of mutual complementary of different genders' advantage and helpful to broaden students' train of thought. In spoken English test, teachers should rationally arrange the proportion of different test forms (e.g. conversation, speech or debate) and offer more opportunities of expression for boys. At the same time, teachers should adjust assessment standard appropriately and give more encouraging feedback in order to strengthen boys' confidence. In this way, teachers can cultivate boys' sensitivity to pragmatic knowledge and improve their culture awareness through communication and reflection.

\subsubsection{Making Best Use of Internet}

Since it is hard for the teachers and the postgraduates to go abroad to learn the target language during the academic university life, Language teachers should be encouraged to integrate the Internet into their classes. The computer is now popularly used in most language classroom and the Internet is also widely used as teachers become more familiar with it. Both teachers and students need to know more about how to use the Internet tools appropriately so that they can achieve maximum benefits. Furthermore, foreign language teachers should exchange ideas about the class design and the procedures through Internet.

The Internet opens pathways to authentic materials and dynamic communications with native speakers around the world and it makes easier for the teacher and the postgraduates to communicate each other after classes through Internet by using QQ ( a popular Chinese internet portal similar to MSN), MSN and emails. Besides the convenience of communication, the Internet also serves as a great tool of retrieving and accessing information, for over $80 \%$ of its information is in English. That is, the postgraduates can get all kinds of information they want such as historical, geographical, economic, cultural, social, and political information from English speaking countries; furthermore, the postgraduates can use it as a platform to meet their own demands such as delivering essays, or opinions. All this would help the postgraduates immerse into the culture of the target language.

A language teacher may instruct learners how to use searching engines such as Google and Baidu to pick out useful information, which could help build up the postgraduates' logic skills. As a result, it helps the postgraduates to practice reading skills and strategies. 
The use of the Internet offers many advantages to the postgraduates. It evokes learners' interest and expands their vision. Most important of all, it's dynamic and autonomous! That's why almost all the postgraduates in the interview choose Internet as a tool to improve their pragmatic competence.

\section{Conclusions}

The study covers the findings as follows: Up to now, the general level of non-English-major postgraduates' pragmatic competence is quite low at present, but with their developing cultural awareness, they do a better job in sociopragmatic competence than pragmalinguistic competence; There are significant differences between genders and their pragmatic competence, with the females' pragmatic competence higher than males', while the differences in majors, age and working experience are not so significant in the participants' English pragmatic competence.

The findings in this study suggest a number of implications and extensions for the classroom. In order to improve the postgraduates' pragmatic competence, it is not enough that we teachers only pay attention to sentence-analysis or ask them to listen and speak English as often as possible. Practically, the research on non-English-major postgraduates' pragmatic competence will benefit English teaching in three aspects: First, the results of the present research give teachers a clear idea about the students' level of pragmatic competence. They will reflect their teaching methods, attaching more importance to students' pragmatic competence development; second, since the teachers often teach language out of context, the postgraduates limit English learning to English textbook learning guided by English test. The research will help the postgraduates to develop a good study attitude and set reasonable study goals; third, there're so many individual differences, teachers should adjust their attitude and make full use of authentic materials and various teaching resources to make the English class more effective.

As to individual differences in pragmatic competence, a consensus has almost been reached that it appears somewhat difficult to predict which variables will be related to which aspects of L2 pragmatic competence positively or negatively. Deeper research is needed to explore in this area.

In the future, it would be helpful to study strategies for pragmatic competence development by adopting a variety of approaches and methods, such as diaries, observation, computer tracking and verbal report. More useful suggestions and statistical support should be provided for pragmatic competence instruction in China and further research is desperately needed to find out the patterns of pragmatic competence development of the postgraduates and the factors influencing it in order to get a deep understanding about the nature of pragmatic competence.

\section{References}

Blum-Kulka, S., House, J. \& Kasper,G.. (1989). Investigating Cross-Cultural Pragmatics: An Introductory Overview. In Blum-Kulka, S., House, J. \& Kasper, G (Eds), Cross-Cultural Pragmatics: Requests and Apologies. Ablex: New Jersey.

Bialystok, E.S. (1993). Symbolic Representation and Attentional Control in Pragmatic Competence. In Kasper, G. \& Blum-Kulka, S. (Eds). Interlanguage Pragmatics (p.21-42). Oxford: Oxford University Press, 43-57.

Byram,M.\&Esarte-Sarries,V. (1991). Investigating Cultural Studies in Foreign Language Teaching: A Book for Teachers. Clevedon, Avon England, Philadelphia: Multilingual Matters Ltd.

Birdsong, D. (1992). Ultimate attainment in second language acquisition. Language Learning, 68, 706-755. https://doi.org/10.1353/lan.1992.0035; https://doi.org/10.2307/416851

Buffery, A. W. H. \& Gray, J. (1972). Sex-difference in the development of spatial and linguistic skills .In Ounsted, C. ed. Gender Differences: Their Ontogeny and Significance. Edinburgh: Churchill Livingstone, 171-180.

Chomsky, N. (1977). Essays on Form and Interpretation. New York: North-Holland.

Dörnyei, Z. (2005). The psychology of the language learner: Individual differences in second language acquisition. Mahwah, NJ: Lawrence Erlbaum.

Diller, K. (1981). (ed.) Individual Differences and Universals in Language Learning Aptitude. Rowley, MA: Newbury House, 3-21.

DeKeyser, R. M. (2000). The robustness of critical period effects in second language acquisition. Studies in Second Language Acquisition, 22, 499-533.

Ellis, R. (1994). Understanding Second Language Acquisition. Shanghai: Shanghai Foreign Language Education Press.

Ellis R. (1994). The Study of Second Language Acquisition. Oxford: Oxford University Press.

Ehrman, M.E., Leaver B. L., \& Oxford, R. L. (2003). A brief overview of individual differences in second language 
learning. System, 31, 313-330. https://doi.org/10.1016/S0346-251X(03)00045-9

Gottman, J. M. \& Levenson, R.L. (1988). The Social Psychophysiology of Marriage. In Noller, P., (Ed). Perspectives on Marital Interaction. Clevedon, England: Multilingual Matters Ltd, 182-199.

Halpern, D. F. (2000). Sex differences in cognitive abilities (3rd edn.). Mahwah, NJ: Lawrence Erlbaum.

Holmes, J. (1992). Women's Talk in Public Context. Discourse and Society, 2, 173-50. https://doi.org/10.1177/0957926592003002001

Kimura, D. (1992). Sex differences in the brain. Sci Am, 267, 119-125. https://doi.org/10.1038/scientificamerican0992-118

Long, M. (1990). Maturational Constraints on Language Development. Studies in Second Language Acquisition, 12, 251-285. https://doi.org/10.1017/S0272263100009165

Lenneberg, E. (1967). Biological foundations of language. New York: John Wiley and Sons.

Leech, G. N. (1983). Principles of Pragmatics . London: Longman, 1-35.

Newport, E. (1990). Maturational constraints on language learning. Cognitive Science, 14, 11-28. https://doi.org/10.1207/s15516709cog1401_2

Oyama, S. (1976). A sensitive period for the acquisition of nonnative phonological system. Journal of Psycholinguistic Research, 5, 261 -284. https://doi.org/10.1007/BF01067377

Oxford, R. (1990). Language Learning Strategies: What Every Teacher Should Know. Boston, MA: Heinle and Heinle, 15, 86-150.

Patkowski, M. (1980). The sensitive period for the acquisition of syntax in a second language. Language Learning, 30, 449-472. https://doi.org/10.1111/j.1467-1770.1980.tb00328.x

Skehan, P. (1989). Individual differences in second language learning. London: Edward Arnold.

Tannen,D. (1987). That's not What I Mean! How Conversational Style Makes or Breakes Relationship. New York: Ballantine

Thomas, J. (1983). Cross-cultural Pragmatic Failure. Applied Linguistics, 2, 91-112. https://doi.org/10.1093/applin/4.2.91

Dai,W.D., \& Chen,L.P. (2005). Factors affecting the development of pragmatic competence in L2. Foreign Language and Their Teaching, (9), 1-5.

Dong, X. H. (1994). A survey and analysis of English majors' pragmatic competence in different stages. Foreign Language Teaching, (3), 91-95.

Gao, Y. (1996). Conrastive analysis and error analysis. Beijing: Beihang University Press.

Gu, R. G.. (1992). Politeness, Pragmatic and Culture. Foreign Language Teaching and Research, (4),10-17.

He, Z. R. (1998). A survey of pragmatics. Hunan Education Publishing House.

He, Z. R. , \& Yan, Zh. (1986). Chinese learners' cross-cultural pragmatic failure--a survey of the differences between Chinese and English. Foreign Language Teaching and Research, (3),52-57.

He, Z. R. (1997). Pragmatics and English learning. Shanghai: Shanghai Foreign language Education Press.

He, Z. R. (2003). Notes on pragmatics. Nan Jing Normal University Press.

Hu, Zh. L. (2003). Linguistics: An advanced course book. Peking University Press.

Hong, G. (1991). A survey on the pragmatic competence and implications for pragmatic English teaching. Foreign Language Teaching and Research, (4), 56-60.

Liu, S. Zh. (1997). Interlanguage Pragmatics:The state of the art and its revelation to research in China. Modern Foreign Language, (3), 71-80.

Si, L. H. (2001). Interlanguage, Pragmatics competence and cultural teaching. Foreign Language Research, (2), 101-105.

Wang,D.X. (1990). Pragmatic problems in cross-cultural communication. Foreign Language Teaching and Research, (4), 7-11.

Wang,X. M. (2006). How gender difference affects EFL learners' linguistic and pragmatic competence. Foreign Language and Literature Studies, (1), 29-33. 


\section{Appendix A}

Gender:

Age:

\section{Pragmatic Competence Questionnaire}

\section{Major:}

Working experience:

Directions: For each problem in this part, you are presented with one situation with four utterances. Read carefully and decide which one is the most appropriate utterance in that situation and circle the right answer.

1. At bus station,

Man: Excuse me, do you know which bus to catch for London Road, please?

Woman: Sorry, I have no idea.

Man: A) It doesn't matter. B) Oh, that's all right.
C) Never mind.
D) Thank you.

(He then went up to another person.)

2. Joyce is talking to her friend, Brenda.

J: I wonder if you'd mind posting this letter for me on your way home, Brenda?

B: A) You're welcome. $\quad$ B) I don't care.
C) I don't mind.
D) Yes, sure.

3. Li had something to tell the manager, Mr. Smith, so he went to his place, entering the room and said,
A) You are not busy, I hope.
B) Got a minute?
C) Can I have a word with you, Mr. Smith?
D) I'm terribly sorry to trouble you, Mr. Smith.

4. A student forgets to return a book to the professor. When meeting the professor, the student would apologize to him by saying
A) I'm terribly sorry. I forgot it.
B) Sorry, I forgot.
C) Oh, I'm very sorry. I completely forgot it.
D) I'm really sorry but I forgot to bring it.

5. Betty is a foreign student in China. She has met Peng Fei.

B: I was told that you won the 100-meter race in the all-city track meeting this morning. Congratulations!
P: A) Just lucky
B) Thank you.

C) I can't say I did well this morning.

D) I could have done better if it hadn't been so cold.

6. Your friend's mother, Mrs. Keeler, asked if you would like something to eat. What would you say to refuse politely?

You: A) Not for the moment, thank you, Mrs. Keeler. I'm full.

B) No, thanks. I've just had lunch.

C) Oh, no, Mrs. Keeler. I haven't long had lunch.

D) I'm full and have no room for any more.

7. When an American friend sends Xu Li a birthday gift and says: "Happy birthday to you."
Xu Li:
A) No, no, I really can't accept it.
B) No, I won't take it.

C) We are friends, you needn't bring a gift for me.

D) How lovely of you. Thank you very much.

8. When introduced to an older professor or to a friend's parents, what would you say?
A)"How are you?"
B) "Hello" and bow.
C)"Hello, it's nice to meet you", and then shake hands. 
D) "Hi! Glad to meet you."

9. On the way to the school cinema, Li saw Professor Blake walking to the cinema, too.

Li: A) Good afternoon, Professor Blake. $\quad$ B) Are you going to the film?

$\begin{array}{ll}\text { C) Where are you going? } & \text { D) You're going to the film, aren't you? }\end{array}$

10. When introducing yourself to someone you don't know at a party what would you say?
A) Hi, I' m...
B) May I introduce myself to you and at the same time I make your acquaintance?
$\begin{array}{lll}\text { C) Hi, I'd like to meet you } & \text { D) Hi, I'm... Do you know many people here? }\end{array}$

11 .One patient goes to see a doctor. At first sight of the patient, the doctor would say
A) Do you have anything to declare, sir?
B) Good morning. May I help you?
C) How have you been getting along recently?
D) What seems to be the problem?

12. You've been asked out to dinner but you don't want to go with the person who invited you. You might say:
A) I don't think so. I already have plans.
B) No, I really don't enjoy being with you.
C) I'm dieting so I mustn't go out to eat.
D) Thanks a lot but I'm busy tonight.

13. Wei Dong met his English teacher, Dr Johns, outside the classroom.
Wei: A) Hi, Dr Johns.
B) Hello, teacher.
C) Morning, Dr Johns.
D) Good morning, teacher Johns.

14. Susan and Meiling are roommates and are getting ready to go to class together.

Meiling: Is it very cold out this morning?

Susan: It's August.

What is Susan saying?
A) It'll be nice and warm today. Don't worry.
B) Yes, even though it's August, it's very cold out.
C) It's so warm for this time of year that it seems like august.
D) Yes, we're sure having crazy weather, aren't we?

15. Meeting unexpectedly a friend he hadn't seen for years, Jim voiced his surprise:
A) No!
B) Yes!
C) $\mathrm{Oh}$ !
D) Hey!

16. American student Tom wants to know if there is a party this evening and asks his Chinese friend Li Ming.
Li Ming: A) Yes.
B) Of course.
C) Of course, there is.
D) It's none of my business.

17. At a party or social occasions, how would you indicate that it was time for you to leave someone's home?
A) I would say, "It's getting late and I'd better be going."
B) I would say, "I'm sorry, I have to leave now."
C) I would wait until the host said something.

D) I would make up an excuse (e.g. I have to get up early tomorrow, etc.) thank the hosts.

18. Li Fang works as a secretary in the International Computer Engineering Corporation. One day she worked very late. Her boss said to her, "Thanks a lot. That's a great help." She replies:
A) It's my pleasure.
B) Never mind.
C) You're welcome.
D) Oh, it's nothing. 
19. At Bill's home. Bill is holding a coffeepot. He wants to ask whether his Chinese friend wants some coffee or not. Bill: Would you like some coffee?

Chinese friend: A) No, please don't go to any troubles.

B) Yes, please. C) Thank you. D) You are welcome.

20. At a dinner,

A: May I have the biscuits?

B: A) Sure (handing along the biscuits).

B) Yes. Help yourself. C) Go ahead. D) Yes, of course.

21.Generally hosts do not offer food more than once or twice because they
A) do not expect you to be hungry.
B) expect you to refuse politely.
C) expect you to dislike the food.

D) expect you to say immediately what you really want.

22. At work, John has just told Bill that they are one man short for the football on Saturday against a neighboring office team.

Bill: Why don't you ask Pete Todd to play? I know he's not very good but there's

no one else to ask, is there?

John: Well, to be honest, Bill, I've already asked him. He just wasn't interested.

Bill: Oh, that's a blow.

By this he means
A) that's a lie.
B) that's a shock.
C) that's a pity.
D) that's a strange.

23. Bob and David are former classmates.

Bob: I've got a job.

David: You haven't!

By this David means

A) "Really?" B) "You are joking." C) "Impossible." D) "No, you haven't got a job."

24. After talking on the phone with Jack for some time, Hsiao Song says, "I've got to go now. Good-bye. By this we can see
A) he was going to stop talking on the telephone.
B) he was going to leave the office.
C) he was going to go home.
D) it was time to leave the office.

25. Two friends discussing an English course.

A: Were you satisfied with that course you took?

B: I didn't think much of it.

By this B means
A) "I was dissatisfied."
B) "I was satisfied."
C) "I hadn't actually begun to think about it."
D) "I don't know." 